\title{
quarto n.2
}

Marília Fornazieri Scarabello

${ }^{1}$ Marilia Fornazieri Scarabello

Formada em Arquitetura e Urbanismo pela Universidade

Presbiteriana Mackenzie.

mabello82@gmail.com 


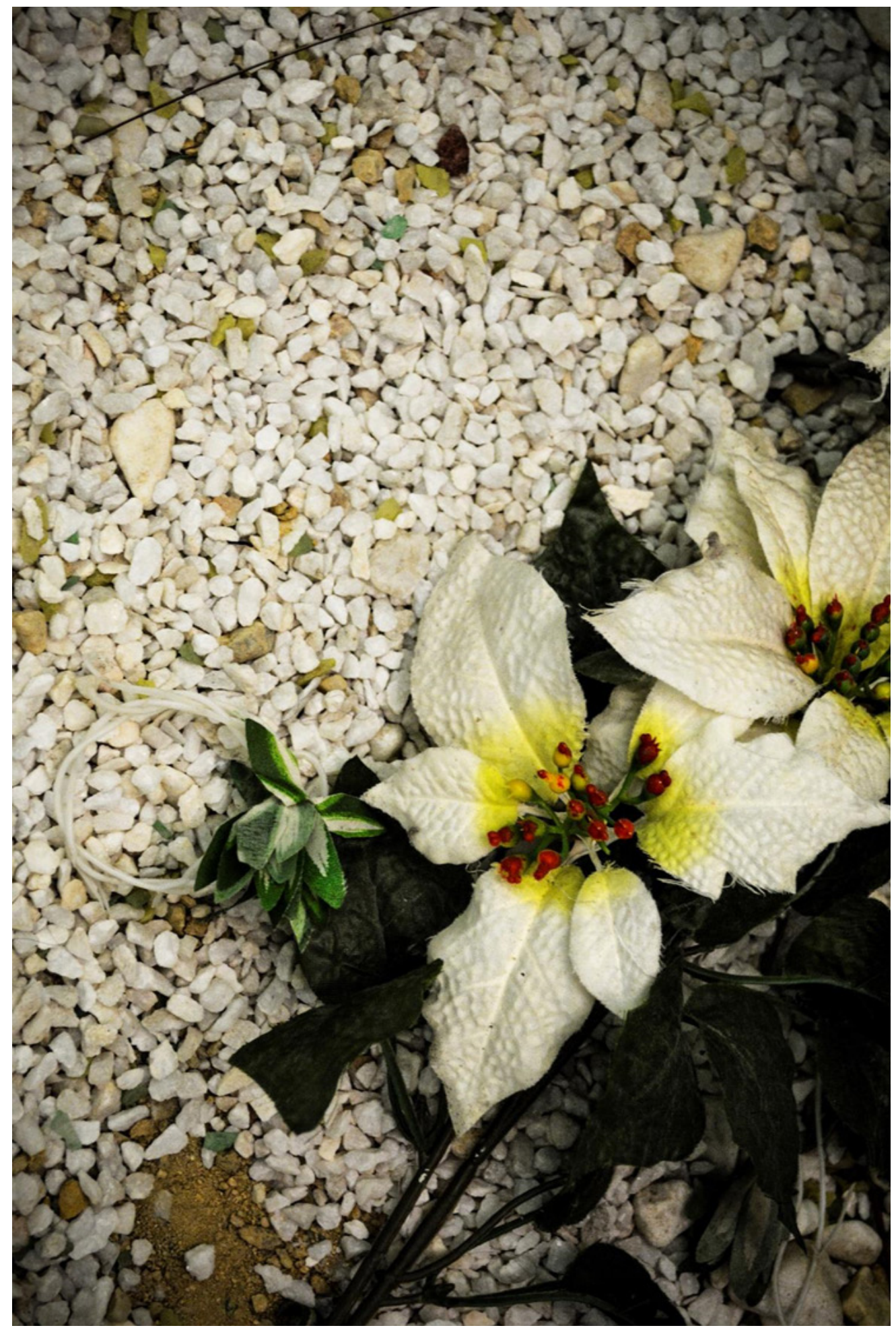



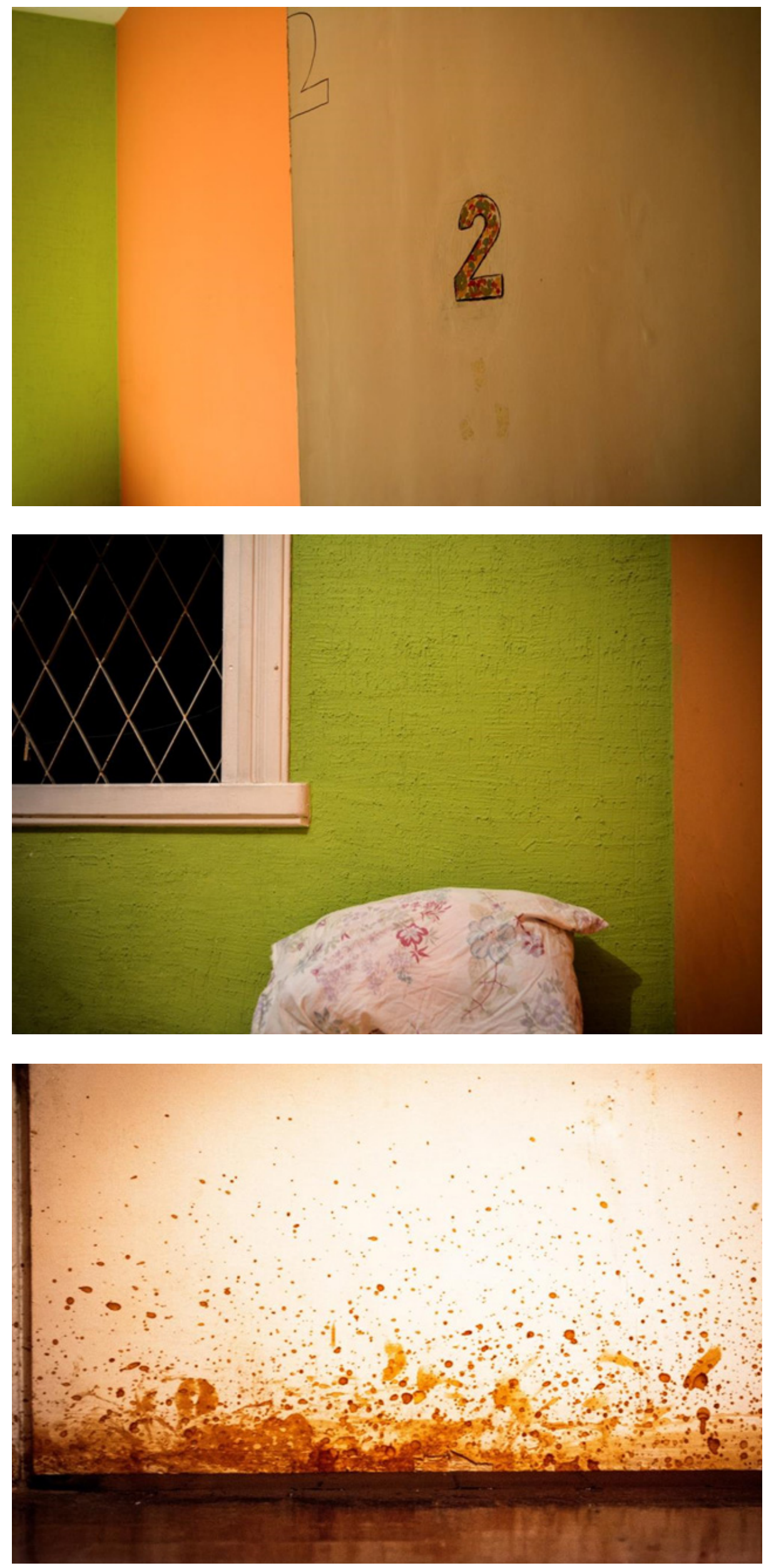

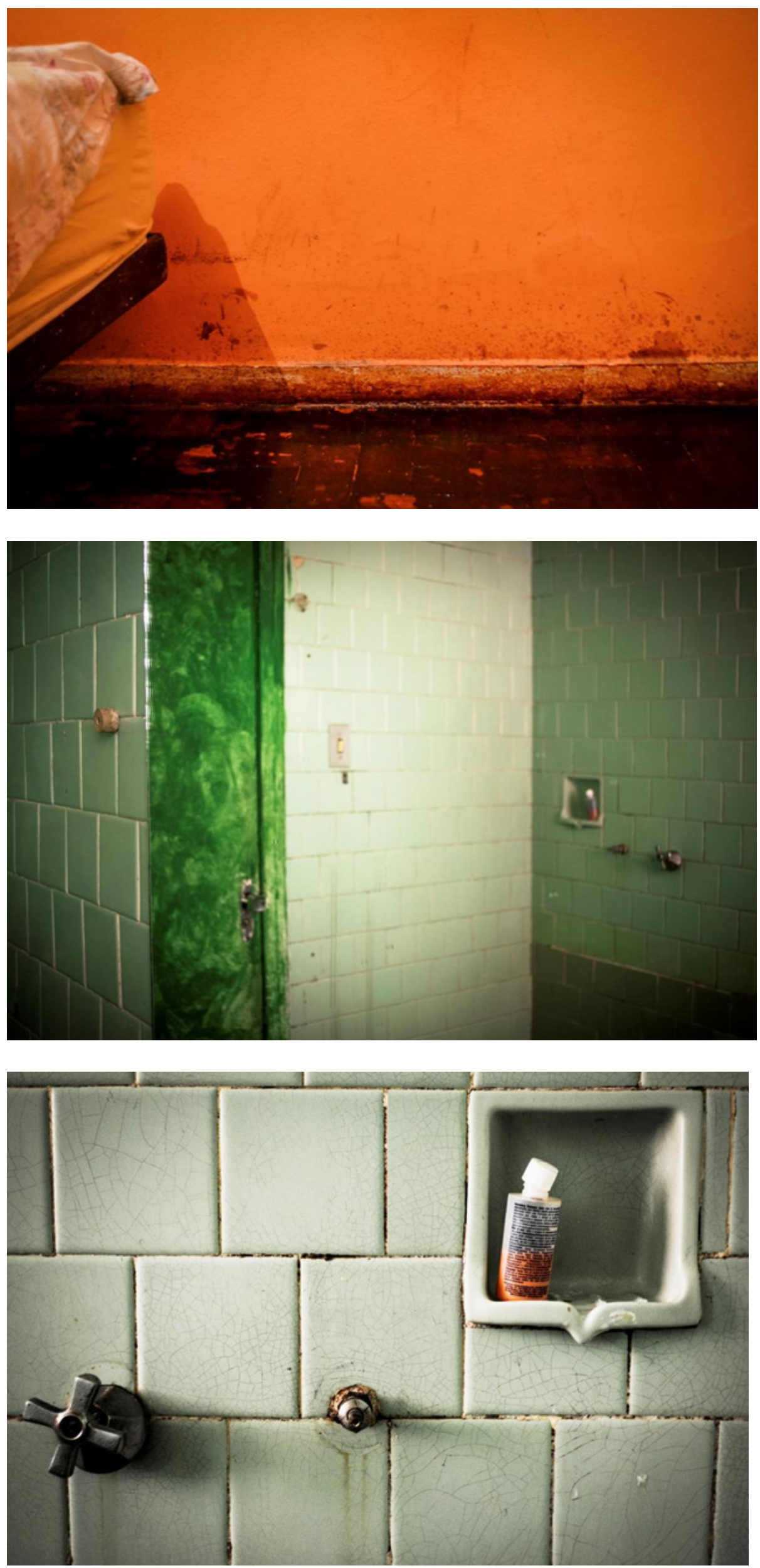

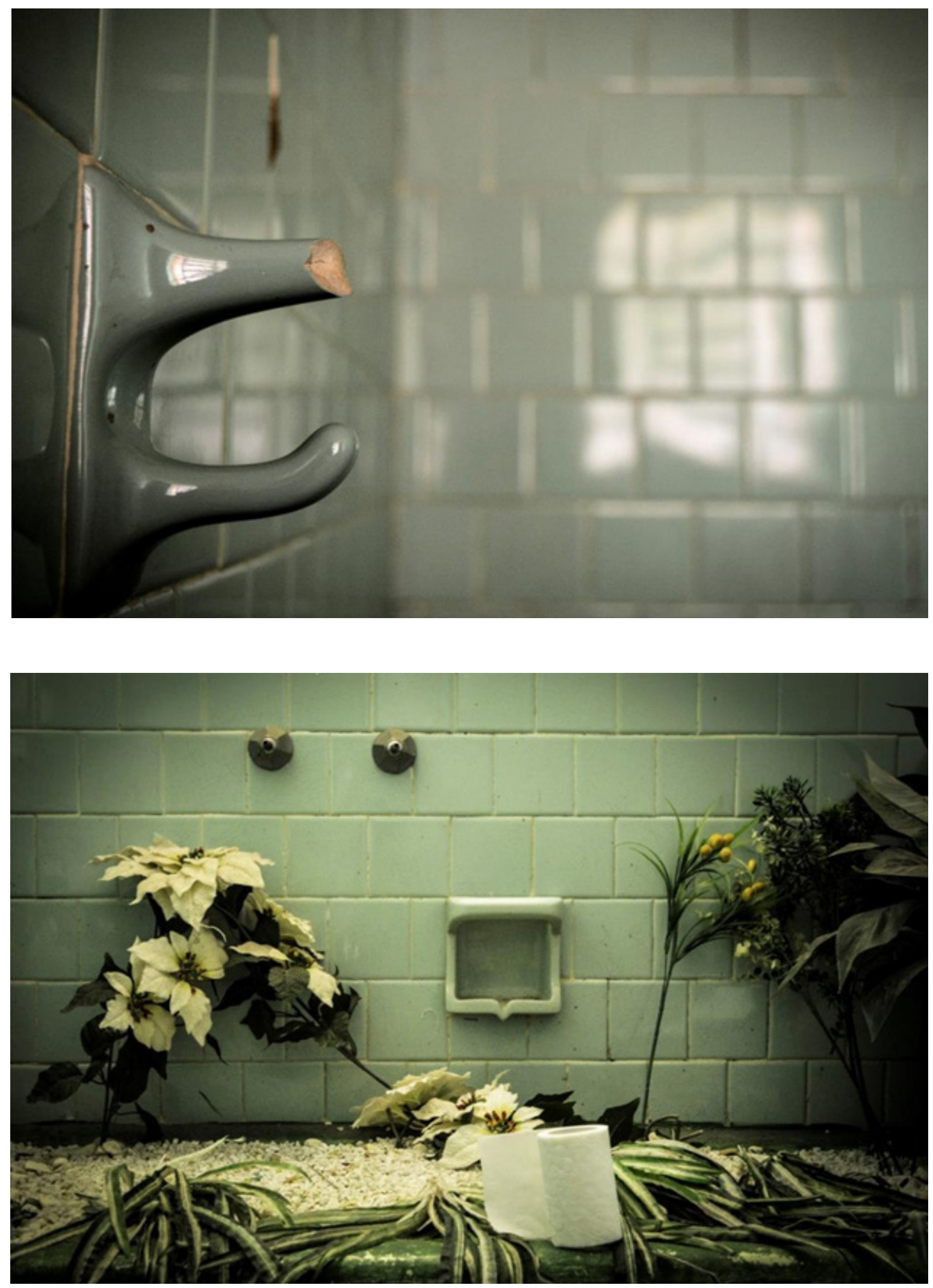